\title{
Comparison of corneal changes after phacoemulsification using BSS Plus versus Lactated Ringer's irrigating solution: a prospective randomised trial
}

\author{
David R Lucena, ${ }^{1}$ Maria S A Ribeiro, ${ }^{1}$ André Messias, ${ }^{1}$ Harley E A Bicas, ${ }^{1}$ \\ Ingrid U Scott, ${ }^{2}$ Rodrigo Jorge ${ }^{1}$
}

'Department of Ophthalmology, Otorhinolaringology and Head \& Neck Surgery, University of São Paulo, Ribeirão Preto, Brazil 2Departments of Ophthalmology and Public Health Sciences, Penn State College of Medicine, Hershey, Pennsylvania, USA

\section{Correspondence to} Dr Rodrigo Jorge, Hospital das Clínicas da Faculdade de Medicina de Ribeirão Preto, Avenida Bandeirantes 3900, Ribeirão Preto-SP, 14049-900, Brazil; rjorge@fmrp.usp.br

Accepted 8 May 2010 Published Online First 28 June 2010

\section{ABSTRACT}

Background/aims To compare two intraocular irrigating solutions, Balanced Salt Solution Plus (BSS Plus) versus Lactated Ringer's (Ringer), for the preservation of corneal integrity after phacoemulsification.

Methods 110 patients undergoing phacoemulsification were randomised to either BSS Plus $(n=55)$ or Ringer $(n=55)$ as the irrigating solution. Patients were examined at baseline and at 1, 8, 15, 30 and 60 days

postoperatively. Evaluations included specular microscopy to evaluate endothelial cell density (ECD) and endothelial cell size variability (CV), and corneal pachymetry for central corneal thickness (CCT) measurement.

Results Groups were well balanced regarding baseline ECD, CV and CCT ( $p>0.05)$. There was no statistically significant difference between ECD reduction in group BSS Plus $13.1 \pm 2.0 \%$ and Ringer $9.2 \pm 1.9 \%(p<0.05)$ at day 60 or in any study visit. There was no statistically significant difference between CV increase in group BSS Plus $23.0 \pm 3.0 \%$ and Ringer $20.2 \pm 4.0 \%(p<0.05)$ at day 60 or in any study visit. CCT was significantly increased $(p<0.05)$ at $1,8,15$ and 30 days postoperatively, returning to baseline at 60 days in both groups. There was no significant difference in CCT increase in both groups at any visit. Interestingly, there were statistically significant correlations between ECD loss and phacoemulsification time $(p<0.0001)$ and ECD loss and irrigation solution volume $(p<0.0001)$ in the Ringer group, but not in the BSS Plus group.

Conclusions Ringers solution was similar to BSS Plus for corneal preservation in atraumatic cataract surgery. However, our study demonstrates that there is a trend towards lower postoperative endothelial cell density for surgeries with longer phacoemulsification time and higher irrigation volumes if Ringer is used.

Trial registration number NCT00801358.

\section{INTRODUCTION}

The corneal endothelium consists of a monolayer of cells on the posterior corneal surface that has limited regeneratory capability after injury. The normal thickness and transparency of the cornea are maintained by a barrier function and the active fluid pump of corneal endothelial cells. ${ }^{1}$ The natural loss of human endothelial cells is approximately $0.6 \%$ each year. ${ }^{2}$ Intraocular manipulation, such as that during phacoemulsification cataract surgery, causes fluid and lens fragment turbulence that can lead to endothelial cell damage. ${ }^{3}$
Solutions initially used for cataract surgery were salt solution, Ringer's solution and plasma-lyte 148. Subsequently, in 1960, more physiological solutions with ionic composition, $\mathrm{pH}$ and osmorality similar to aqueous humour were developed and received the name of balanced salt solution (BSS) ${ }^{4}$. In 1973, a third generation of irrigation solution, named BSS Plus, was developed after studies by Edelhauser and coauthors, ${ }^{5-7}$ who verified that the addition of glutathione, glucose and bicarbonate to the irrigation solution would contribute to endothelial cell function and survival in vitro.

Further, some in vivo studies using different irrigating solutions show that postoperative corneal thickness and endothelial cell count do not depend on irrigation volume and time but rather depend on the solution's chemical composition..$^{8-11}$ In fact, studies show that enriched balanced salt solutions such as BSS Plus (glucose glutathione bicarbonate solution) provide characteristics similar to those of the aqueous humour to maintain constant intraocular conditions. ${ }^{8} 1213$ However, dextrose bicarbonate Lactated Ringer's solution for irrigation has been reported to be as effective as enriched BSS during cataract surgery, ${ }^{14}$ and some authors consider operating time and irrigation volume to be important clinical factors for endothelial cell loss during phacoemulsification cataract surgery. ${ }^{15} 16$

Based on the above presented conflicting information and the necessity for optimising costs in cataract surgery, especially for very poor regions from developing countries, and considering that Lactated Ringer's is 30 times cheaper than BSS Plus, ${ }^{17}$ we designed this prospective masked trial to investigate for differences in preservation of corneal integrity after phacoemulsification cataract surgery using two intraocular irrigating solutions.

\section{MATERIALS AND METHODS}

The study protocol adhered to the tenets of the Declaration of Helsinki and was approved by the local Institutional Review Board and registered at http://ClinicalTrials.gov (NCT00801359).

\section{Patient eligibility and baseline evaluation}

Participation in a prospective, double-masked trial was offered to all patients with age-related cataract scheduled to undergo phacoemulsification with intraocular lens (IOL) implantation at the Division of Cataract Surgery from Centro Avançado de Retina e Catarata, from 1 January to 31 May 2008. 
Exclusion criteria included: (1) types of cataract other than age-related (eg, secondary or congenital); (2) previous ocular surgery; (3) previous corneal disease; (4) anterior chamber cells or flare; (5) any condition that impeded corneal evaluation by specular microscopy and pachymetry or follow-up.

All patients underwent an initial screening visit which included a detailed ophthalmic evaluation with Snellen BCVA measurement, applanation tonometry measured with a Goldmann tonometer, biomicroscopy of the anterior segment, dilated biomicroscopic fundus examination and binocular indirect ophthalmoscopy.

Patients who met the eligibility criteria were informed verbally and in writing of the potential risks and benefits of the use of the two irrigation solutions, and those patients who agreed to participate signed a written informed consent form. For patients who accepted study participation, the screening visit was used as the baseline examination, which occurred 1-7 days before surgery. If both eyes were eligible for study participation, the eye with worse BCVA was included in the study.

Lens nuclear opalescence was graded using slit-lamp evaluation in a scale from 1 to 4 by a single examiner (MSAR). For IOL power measurement, keratometry was performed using a Topcon autorefractor (KR8800, Topcon, Tokyo, Japan), and axial length was measured using Alcon OcuScan RXP A-Scan Biometry (Alcon, Fortworth, Texas).

Central corneal thickness was measured using an optical pachymeter (Topcon SP2000P). For each eye, the average of three measurements performed by the same person was calculated. This ensures a precision of $\pm 10 \mu \mathrm{m}$ (manufacturer information).

The corneal endothelium was examined with a non-contact specular microscope (Topcon SP2000P). Three photographs were taken per eye at each examination, and the mean of measurements was calculated. With this semiautomatic method, the operator hand-digitised the centre of each cell (centre method). Corneal endothelial morphology was calculated from a cluster of 55 cells from each photo as described elsewhere ${ }^{18}$ and illustrated in figure 1.

The following variables were measured: (1) central endothelial cell density (ECD) defined as the number of cells per $\mathrm{mm}^{2}$; (2) central endothelial cell size variability or the coefficient of variation (CV). This variable is defined as $\mathrm{SD} / \mu \mathrm{CS}$ (where SD is the standard deviation of the cell size, and $\mu \mathrm{CS}$ is the mean cell size) and is expressed as a percentage.

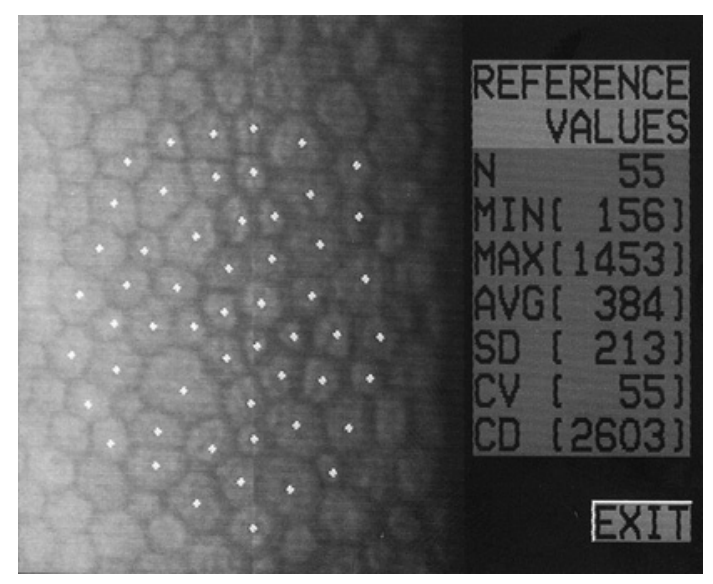

Figure 1 Specular microscopy picture illustrating the 'centre method' used for corneal morphology analysis in patients from Balanced Salt Solution Plus and Ringer groups in all study periods.

\section{Treatment assignment and surgical technique}

After baseline evaluation, patients were randomised in groups of five. The technician was asked to pick up one of two identical opaque envelopes, one containing the designation for phacoemulsification surgery using BSS Plus irrigation solution (BSS Plus group; BSS Plus, Alcon, Fortworth, Texas) and the other containing the designation for phacoemulsification surgery using Lactated Ringer's solution (Ringer group; Ringer Lactato, Baxter, São Paulo, Brazil). The next five included patients were automatically assigned to the treatment group specified in the second envelope.

Eyes were anaesthetised with topical proximetacaine (Anestalcon, Alcon, Fortworth, Texas), one drop every 10 min for $30 \mathrm{~min}$ before surgery. Five millilitres of xylocaine gel $2 \%$ (Cristalia, São Paulo, Brazil) was applied 5 min before surgery, as well as one drop of topical povidone-iodine 5\% (Ophthalmos, São Paulo, Brazil). The patient was draped. A $2.75 \mathrm{~mm}$ clear cornea incision was made with a diamond blade, the anterior chamber was filled with $2 \%$ methylcellulose (Vistagel, Croma Pharma, Austria), and an anterior capsulorrexis was made using Utrata forceps (Storz, Heidelberg, Germany). For phacoemulsification, a horizontal phaco-chop technique was employed using an Ozil tip (Infinity machine, Alcon) and the following parameters: ultrasound power output of $30 \%$; vacuum pressure set at $300 \mathrm{~mm} \mathrm{Hg}$ and aspiration rate at $30 \mathrm{ml} / \mathrm{min}$, followed by aspiration of lens cortex remnants. An acrylic, foldable hydrophobic intraocular lens (Acrysof SA60AT, Alcon) was inserted into the capsular bag through the $2.75 \mathrm{~mm}$ clear corneal incision. No suture was added in any case. The time of ultrasound use and its potency (kept at 30\% for all cases), volume of irrigation solution used and operating time were noted for each surgery procedure, as well as intraoperative complications such as Descemet detachment, iris trauma and posterior capsule rupture.

All surgeries were performed by the same physician (DRL) under sterile conditions. The physician was not masked and knew the type of irrigation solution that was being used for each patient. Postoperatively, $0.3 \%$ ciprofloxacin (Ciloxan, Alcon) three times per day and prednisolone acetate 1\% (Predforte, Allergan, Irvine, California) four times per day were used for 4 weeks.

\section{Follow-up examinations and outcome measures}

Patients were scheduled for follow-up examinations at postoperative days $1,8,15( \pm 1), 30( \pm 2)$ and $60( \pm 2)$. At these visits, patients underwent complete ophthalmic examination using the same procedures as at baseline. All baseline and postoperative evaluations were performed by a masked ophthalmologist (MSAL) who was not aware of the irrigation solution used during surgery.

\section{Statistical analysis}

Comparisons between groups at baseline (ie, patient age, surgery duration, etc) were performed with non-paired t tests. Cataract nucleus scores were compared with a contingency analysis followed by a Pearson $\chi^{2}$ test. For data retrieved at postoperative days 1, 8, 15, 30 and 60, intraindividual differences from baseline were calculated, and a statistically significant effect was defined as a difference for zero for intraindividual mean differences. Statistical analyses have been performed using JMP 7.0.2 (SAS Institute 2007; SAS Institute, Cary, North Carolina) software.

Considering the mean and SD (16\% and $4 \%$ respectively) for the intraindividual difference in endothelial cell density found in a previous study, ${ }^{19}$ we could estimate that, with a sample of 
50 patients per group, the minimal detectable difference would be $2.4 \%$ (power $=80 \%$ ), which is considered well suited for the purposes of this study.

\section{RESULTS}

Between January 2008 and October 2008, 100 patients completed the 60 -day study period: 50 patients from each group. Ten patients (five from the BSS Plus group and five from the Ringer group) were excluded because they had two consecutive missed visits.

There were no significant differences between groups with respect to patient age, gender, baseline visual acuity, intraocular pressure, cataract grading, time of ultrasound use and volume of irrigation solution employed (table 1). Final visual acuity also did not differ significantly. Forty-eight patients had cataract in both eyes, and the eye with worse visual acuity was selected for the study.

\section{Endothelial cell density (ECD)}

The preoperative mean ( \pm SEM) ECD was $2728.9 \pm 70.9$ cells $/ \mathrm{mm}^{2}$ and $2836.6 \pm 50.3$ cells $/ \mathrm{mm}^{2}$ in the BSS Plus and Ringer groups, respectively $(p=0.1092)$. A significant reduction from baseline in ECD was observed at each postoperative study visit in both groups. There was no statistically significant difference in ECD reduction between BSS Plus and Ringer groups at any study visit (figure $2 \mathrm{~A}$, table 2).

A statistically significant linear correlation was observed between ECD loss and phacoemulsification time for the Ringer group $(p<0.0001)$ throughout the 60 -day study period. Taking results from the last visit (60 days postoperatively), the coefficient of correlation $\left(r^{2}=0.313\right)$ demonstrates that the linear model explains only approximately one-third of the variation around the mean. Nevertheless, the observed significance probability $(\mathrm{p}=0.0001)$ can be considered evidence of a regression effect (figure 3). Thus, considering the model: $\mathrm{ECD}_{\text {Change }}=\mathrm{a}^{*} \mathrm{US}_{\text {Time }}+\mathrm{b}$, the parameter a found for the Ringer group at 60 days after surgery is: $a=-6.3 \pm 1.3\left(\right.$ cell $\left./ \mathrm{mm}^{2}\right) / \mathrm{s}$, meaning that for each $1 \mathrm{~s}$ of phacoemulsification time, ECD loss increases by approximately 6 cells $/ \mathrm{mm}^{2}$. In contrast, there was no significant correlation between ECD loss and phacoemulsification time in the BSS Plus group at any study visit. For this group at day 60 after surgery,

Table 1 Demographic and clinical characteristics

\begin{tabular}{|c|c|c|}
\hline & $\begin{array}{l}\text { Balanced Salt } \\
\text { Solution Plus }\end{array}$ & Ringer \\
\hline $\begin{array}{l}\text { Age (years) } \\
(p>0.05)\end{array}$ & $63.0 \pm 1.6$ & $65.3 \pm 1.7$ \\
\hline $\begin{array}{l}\text { Gender } \\
(p>0.05)\end{array}$ & 34 females & 36 females \\
\hline $\begin{array}{l}\text { Visual acuity at baseline }(\log M A R) \\
(p>0.05)\end{array}$ & $\begin{array}{l}0.52 \pm 0.02 \\
(20 / 62)\end{array}$ & $\begin{array}{l}0.51 \pm 0.03 \\
(20 / 57)\end{array}$ \\
\hline $\begin{array}{l}\text { Visual acuity at postoperative day } 60 \text { visit (logMAR) } \\
(p>0.05)\end{array}$ & $\begin{array}{l}0.04 \pm 0.01 \\
(20 / 22)\end{array}$ & $\begin{array}{l}0.03 \pm 0.01 \\
(20 / 21)\end{array}$ \\
\hline $\begin{array}{l}\text { Phacoemulsification time }(s) \\
(p>0.05)\end{array}$ & $32.9 \pm 4.9$ & $32.6 \pm 4.9$ \\
\hline $\begin{array}{l}\text { Volume of irrigating solution employed (ml) } \\
(\mathrm{p}>0.05)\end{array}$ & $124.8 \pm 8.3$ & $129.9 \pm 8.4$ \\
\hline $\begin{array}{l}\text { Intraocular pressure at baseline }(\mathrm{mmHg}) \\
(\mathrm{p}>0.05)\end{array}$ & $16 \pm 3$ & $16 \pm 4$ \\
\hline $\begin{array}{l}\text { Cataract nucleus opalescence (score): } \\
\text { No of patients }\end{array}$ & $\begin{array}{l}\text { (1) } 10 \\
\text { (2) } 22\end{array}$ & $\begin{array}{l}\text { (1) } 14 \\
\text { (2) } 20\end{array}$ \\
\hline Pearson test: $\chi^{2}=6.07 ; \mathrm{p}=0.1081$ & $\begin{array}{l}\text { (3) } 13 \\
\text { (4) } 5\end{array}$ & $\begin{array}{l}\text { (3) } 16 \\
\text { (4) } 0\end{array}$ \\
\hline
\end{tabular}

Values presented as mean \pm SEM.
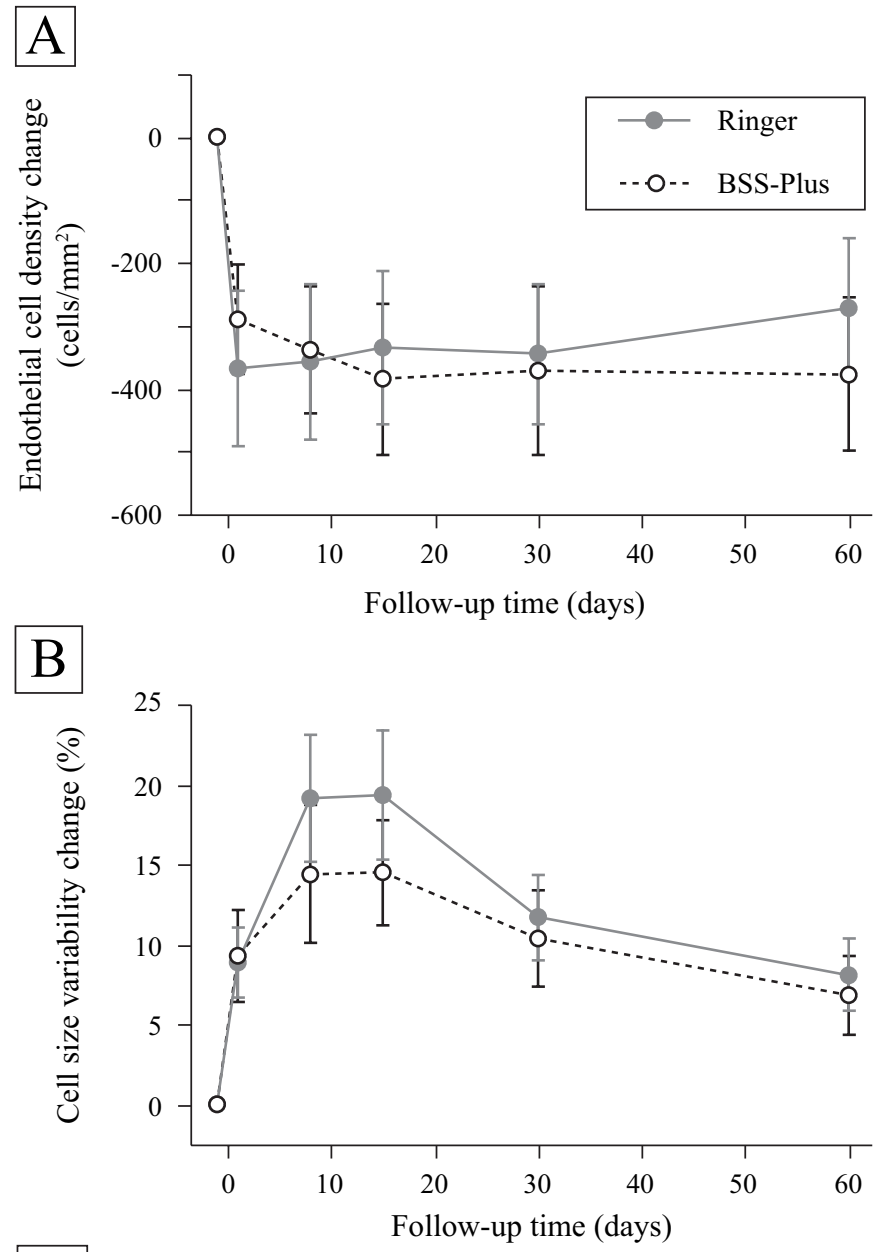

$\mathrm{C}$

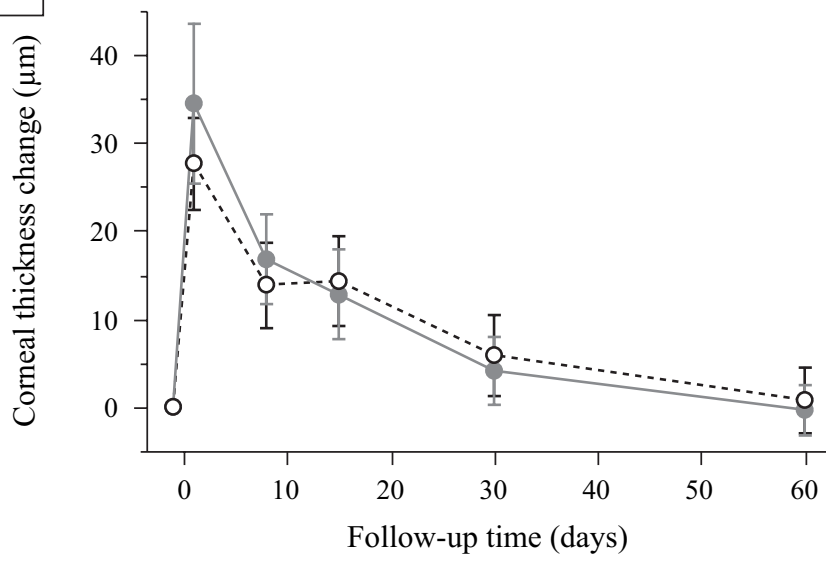

Figure 2 (A) Endothelial cell density, (B) central corneal thickness and (C) central corneal endothelial cell size variability changes after surgery plotted against follow-up time (days 1, 8, 15, 30 and 60). Filled grey circles connected by grey lines represent data from the Lactated Ringer's group, while unfilled circles connected with dashed lines are from the Balanced Salt Solution Plus (BSS-Plus) group. Error bars are the $95 \%$ confidence limits of the mean. Note that there is no statistically significant difference between the two groups at any study visit with respect to the three parameters.

$r^{2}$ was 0.03 and $p=0.2364$, indicating that the linear model fits no better than the overall response mean.

There is also a statistically significant correlation between ECD loss and the total volume of Ringer used. Linear model parameters for the Ringer group at 60 days postoperatively are 
Table 2 Mean \pm SEM endothelial cell density, central corneal thickness and cell size coefficient of variability and the intraindividual differences during follow-up

\begin{tabular}{|c|c|c|c|c|}
\hline \multirow[b]{2}{*}{$\begin{array}{l}\text { Follow-up } \\
\text { (days) }\end{array}$} & \multicolumn{2}{|c|}{ Balanced Salt Solution Plus } & \multicolumn{2}{|l|}{ Ringer } \\
\hline & $\begin{array}{l}\text { Data } \\
\text { (cells/m²) }\end{array}$ & $\begin{array}{l}\text { Intraindividual } \\
\text { difference (\%) }\end{array}$ & $\begin{array}{l}\text { Data } \\
\text { (cells/m } / \mathbf{m}^{2} \text { ) }\end{array}$ & $\begin{array}{l}\text { Intraindividual } \\
\text { difference (\%) }\end{array}$ \\
\hline \multicolumn{5}{|c|}{ Endothelial cell density } \\
\hline Baseline & $2836.6 \pm 50.3$ & & $2728.9 \pm 70.9$ & \\
\hline 1 & $2468.3 \pm 68.3$ & $12.7 \pm 2.1$ & $2438.6 \pm 67.5$ & $10.3 \pm 1.5$ \\
\hline 8 & $2479.2 \pm 64.1$ & $12.1 \pm 2.1$ & $2390.2 \pm 71.8$ & $12.1 \pm 1.8$ \\
\hline 15 & $2501.5 \pm 62.6$ & $11.3 \pm 2.1$ & $2344.3 \pm 71.6$ & $13.5 \pm 2.0$ \\
\hline 30 & $2492.0 \pm 60.3$ & $11.7 \pm 1.9$ & $2357.0 \pm 76.8$ & $13.0 \pm 2.3$ \\
\hline 60 & $2564.2 \pm 61.7$ & $9.2 \pm 1.9$ & $2350.7 \pm 69.3$ & $13.1 \pm 2.0$ \\
\hline \multicolumn{5}{|c|}{ Cell size coefficient of variability } \\
\hline Baseline & $42.3 \pm 1.2$ & & $41.6 \pm 1.4$ & \\
\hline 1 & $51.6 \pm 1.6$ & $24.7 \pm 4.3$ & $50.4 \pm 1.4$ & $24.1 \pm 3.2$ \\
\hline 8 & $56.7 \pm 2.2$ & $37.2 \pm 5.5$ & $60.7 \pm 2.1$ & $49.7 \pm 5.2$ \\
\hline 15 & $56.8 \pm 1.4$ & $39.1 \pm 5.0$ & $60.9 \pm 2.0$ & $51.8 \pm 6.1$ \\
\hline 30 & $52.7 \pm 1.2$ & $29.2 \pm 4.9$ & $53.3 \pm 1.2$ & $32.5 \pm 3.7$ \\
\hline 60 & $49.1 \pm 1.0$ & $20.2 \pm 4.0$ & $49.6 \pm 1.1$ & $23.0 \pm 3.0$ \\
\hline \multicolumn{5}{|c|}{ Central corneal thickness } \\
\hline Baseline & $515.7 \pm 4.4$ & & $513.1 \pm 4.2$ & \\
\hline 1 & $550.2 \pm 6.9$ & $6.7 \pm 0.9$ & $540.8 \pm 4.8$ & $5.4 \pm 0.5$ \\
\hline 8 & $532.4 \pm 4.9$ & $3.3 \pm 0.5$ & $527.0 \pm 4.7$ & $2.7 \pm 0.5$ \\
\hline 15 & $528.4 \pm 4.7$ & $2.5 \pm 0.5$ & $527.4 \pm 4.9$ & $2.8 \pm 0.5$ \\
\hline 30 & $519.8 \pm 4.2$ & $0.9 \pm 0.4$ & $519.0 \pm 4.5$ & $1.2 \pm 0.4$ \\
\hline 60 & $515.3 \pm 4.5$ & $-0.1 \pm 0.3$ & $513.9 \pm 4.4$ & $0.2 \pm 0.4$ \\
\hline
\end{tabular}

$\mathrm{a}=-6.7 \pm 0.5\left(\right.$ cells $\left./ \mathrm{mm}^{2}\right) / \mathrm{ml}, \quad\left(\mathrm{r}^{2}=0.407 ; \mathrm{p}<0.0001\right)$. Thus, for each $1 \mathrm{ml}$ of Ringer used, ECD loss increases approximately 7 cells $/ \mathrm{mm}^{2}$. In contrast, there was no significant correlation between BSS Plus used and ECD loss at any study period. For this group at day 60 after surgery, $r^{2}$ was 0.038 and $p=0.1736$, indicating that the linear model fits no better than the overall response mean (figure 3 ).

\section{Corneal endothelial size variability (CV)}

The preoperative mean CV was $42.3 \pm 1.2 \%$ and $41.6 \pm 1.4 \%$ in the BSS Plus and Ringer groups, respectively $(p=0.6503)$. There was a significant increase in CV in both groups at 1, 8, 15, 30 and 60 days after surgery. There was no statistically significant difference in $\mathrm{CV}$ between the groups at any study visit (figure 2C, table 2). There was no statistically significant correlation between $\mathrm{CV}$ change and phacoemulsification time or total volume of irrigation volume used in either group.

\section{Central corneal thickness (CCT)}

The mean baseline CCT was 515.7 \pm 4.4 and $513.1 \pm 4.2 \mu \mathrm{m}$ in the BSS Plus and Ringer groups, respectively $(p=0.3364)$. There was a significant increase in CCT in both groups at 1, 8, 15 and 30 days after surgery $(p<0.05)$. The mean CCT returned to baseline values 60 days after surgery in both groups $(p>0.05)$. There was no statistically significant difference between the two groups at any study visit (figure $2 \mathrm{~B}$, table 2 ). There was no statistically significant correlation between CCT change and phacoemulsification time or total volume of irrigation volume used in either group.

\section{Intraoperative and postoperative complications}

There were no cases of Descemet membrane detachment, iris trauma, posterior capsule rupture or endophthalmitis during the study.

\section{DISCUSSION}

The results of the current study show, as clearly plotted in figure 1, that BSS Plus is similar to Lactated Ringer's with respect to the clinical parameters (ECD, CCT and CV) that reflect preservation of corneal integrity following phacoemulsification cataract surgery with posterior chamber IOL implantation. It is important to point out that this study included uncomplicated cases performed by an experienced surgeon, who performed all surgeries with less than $180 \mathrm{~s}$ of phacoemulsification time (phacoemulsification power at 30\%) and with less than $150 \mathrm{ml}$ for all surgeries. Kiss et $a l^{20}$ and Puckett et al ${ }^{14}$ reported similar endothelial preservation with the use of BSS Plus or Lactated Ringer's as irrigating solutions for atraumatic cataract surgery by phacoemulsification and extracapsular extraction, respectively. However, the results of these latter two
Figure 3 Endothelial cell density change to baseline at 60 after surgery plotted against phacoemulsification time in groups Balanced Salt Solution Plus (BSS-Plus) (A) and Ringer (C); and surgical irrigation volume in the BSSPlus (B) and Ringer group (D). Circle, results from each patient; lines, best linear fit. No statistically significant correlation was found in the BSS-Plus group, but a statistically significant correlation was found in Ringer.
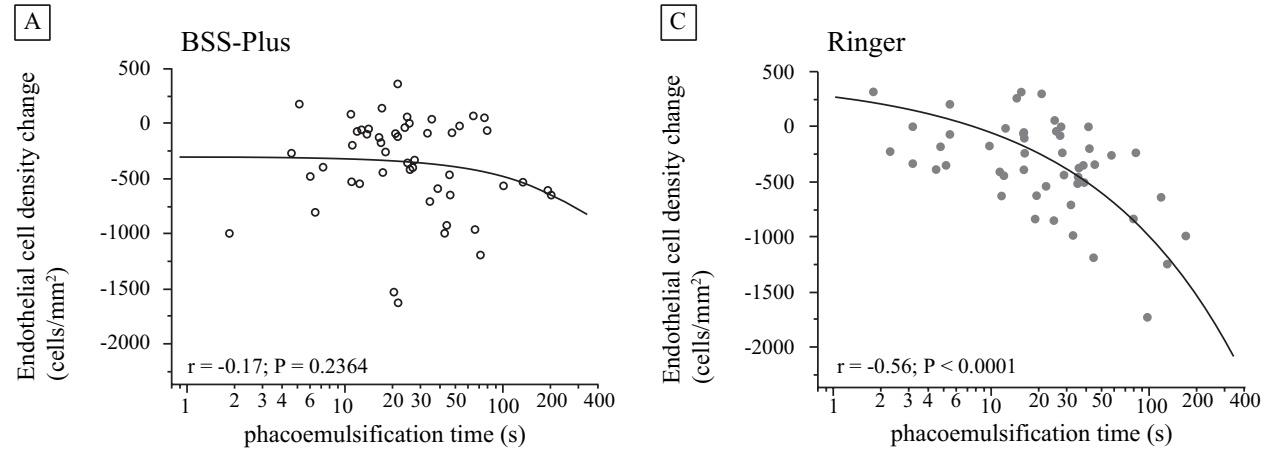

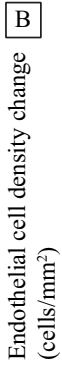
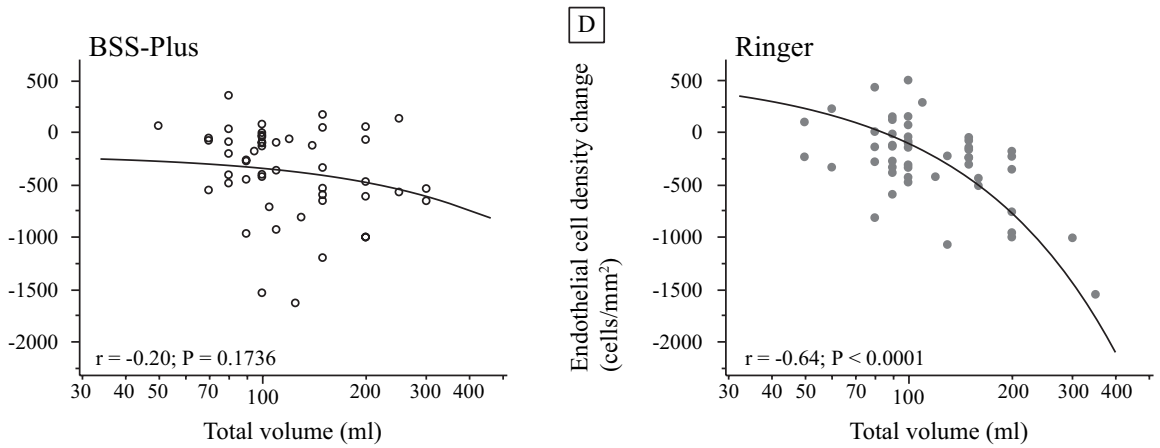
studies are in contrast to data from a study by Joussen et al, ${ }^{21}$ who reported that corneas irrigated with BSS Plus during phacoemulsification were less swollen than corneas irrigated with Ringer's solution on the first postoperative day. Another study, by Vasavada et $a l^{22}$ also reported the same finding, although in this Indian study, standard BSS was used.

On the other hand, the steepness of the endothelial cell density reduction slope in relation to phacoemulsification time and irrigation volume used in the Ringer group (figure 3) demonstrates the trend towards reduced endothelial cell density for surgeries with longer phacoemulsification time and higher volumes of irrigation; this is in contrast to the BSS Plus group, for which the endothelial cell density reduction slope is not so steep, and there is no significant correlation with phacoemulsification time and irrigation volume used. This is consistent with data obtained in studies from Edelhauser et al, ${ }^{67}$ Matsuda et al ${ }^{8}$ and Yagoubi et al, ${ }^{23}$ which demonstrated that the corneal endothelium can be better preserved by using solutions with a composition similar to that of aqueous humour.

In fact, BSS Plus and Lactated Ringer's have common aqueous humour constituents: sodium chloride, potassium chloride, calcium chloride. However, just BSS Plus has magnesium, sodium phosphate, sodium bicarbonate, dextrose and glutathione, which are also present in aqueous humour. The rationale for the abovementioned composition differences that theoretically favour BSS Plus would be: magnesium is essential for the Mg-ATPase endothelial pump; the addition of dextrose would be justified as a natural energy source for endothelial cells ${ }^{24}$, sodium phosphate and bicarbonate are physiological buffers found in aqueous humour, ${ }^{25} 26$ and glutathione is a peptide which is important as an antioxidant and as an agent maintaining the intercellular junctions. 581421 In addition, aqueous humour, BSS Plus and Lactated Ringer's pH and osmolarity are 7.38/304; 7.40/305 and 6.4/260, respectively. 7142127 Consequently, Lactated Ringer's solution is hypotonic and slightly acidic when compared with BSS Plus, which seems to be more physiological, since it has $\mathrm{pH}$ and osmolarity values closer to aqueous humour values.

The results of the current study also confirm the findings of other investigators that ECD is not correlated with CCT on a long-term basis. ${ }^{19} 28$ These data showed that CCT returned to preoperative values after 60 days, despite the endothelial loss, in agreement with data reported by Cheng et $a^{28}$ and Glasser et $a{ }^{12}$ who showed that the functional reserve of a normal endothelium can maintain corneal thickness despite the significant reductions of cell density occurring with age or after intraocular surgery. The thickness of the cornea increases immediately after surgery, when the pump and the barrier functions of the endothelium are compromised, and therefore, the measurement of corneal thickness reveals the extent of the surgically induced endothelial injury. At 1-2 months after surgery, endothelial cell count remains irreversibly changed, but cell function is usually re-established, and there is a proportional increase in endothelial cell size and reduction in corneal pachymetry to preoperative values. ${ }^{20}$

In summary, for uncomplicated phacoemulsification cataract surgeries, Ringer's solution is associated with a corneal endothelial cell reduction similar to BSS Plus, if the surgeon uses limited phacoemulsification time and irrigation volume. Given the 30-fold higher cost of BSS Plus compared with Lactated Ringer's solution, the findings of our study may have a substantial impact on the cost of providing cataract surgery for atraumatic cases. On the other hand, for cataract operations that may require a higher volume of irrigation solution or longer phacoemulsification time, such as dislocated lens, dense cataracts and inexperienced surgeons cases, BSS Plus may contribute to lower endothelial cell loss.

Funding Supported by Conselho Nacional de Pesquisa (CNPq), grant No 306692/2008-2.

\section{Competing interests None.}

Ethics approval Ethics approval was provided by the Comite de Ética em Pesquisa do HCFMRP-USP.

Provenance and peer review Not commissioned; externally peer reviewed.

\section{REFERENCES}

1. Mishima S. Clinical investigations on the corneal endothelium. Ophthalmology 1982;89:525-30.

2. Bourne WM, Nelson LR, Hodge DO. Central corneal endothelial cell changes over a ten-year period. Invest Ophthalmol Vis Sci 1997:38:779-82.

3. Dick HB, Kohnen T, Jacobi FK, et al. Long-term endothelial cell loss following phacoemulsification through a temporal clear corneal incision. J Cataract Refract Surg 1996;22:63-71.

4. Merrill DL, Fleming TC, Girard LJ. The effects of physiologic balanced salt solutions and normal saline on intraocular and extraocular tissues. Am J Ophthalmol 1960;49:895.

5. McCarey BE, Edelhauser HF, Van Horn DL. Functional and structural changes in the corneal endothelium during in vitro perfusion. Invest Ophthalmol 1973;12:410-17.

6. Edelhauser HF, Gonnering R, Van Horn DL. Intraocular irrigating solutions-a comparative study of BSS Plus and Lactated Ringer's solution. Arch Ophthalmol 1978:96:516-20.

7. Edelhauser HF, Van Horn DL, Hyndiuk RA, et al. Intraocular irrigating solutions. Their effect on the corneal endothelium. Arch Ophthalmol 1975;93:648-57.

8. Matsuda M, Kinoshita S, Ohashi Y, et al. Comparison of the effects of intraocular irrigating solutions on the corneal endothelium in intraocular lens implantation. Br J Ophthalmol 1991;75:476-9

9. Araie M, Shirasawa E, Hikita M. Effect of oxidized glutathione on the barrier function of the corneal endothelium. Invest Ophthalmol Vis Sci 1988;29:1884-7.

10. Whikehart DR, Edelhauser HF. Glutathione in rabbit corneal endothelia: the effects of selected perfusion fluids. Invest Ophthalmol Vis Sci 1978;17:455-64.

11. Matsuda M, Tano Y, Edelhauser HF. Comparison of intraocular irrigating solutions used for pars plana vitrectomy and prevention of endothelial cell loss. Jpn $J$ Ophthalmol 1984;28:230-8.

12. Glasser DB, Matsuda M, Ellis JG, et al. Effects of intraocular irrigating solutions on the corneal endothelium after in vivo anterior chamber irrigation. Am J Ophthalmol 1985;99:321-8.

13. Araie M. Barrier function of corneal endothelium and the intraocular irrigating solutions. Arch Ophthalmol 1986;104:435-8.

14. Puckett TR, Peele KA, Howard RS, et al. Intraocular irrigating solutions-a randomized clinical trial of balanced salt solution plus and dextrose bicarbonate lactated ringer's solution. Ophthalmology 1995;102:291-6.

15. O'Grady GE, Alfonso E, Lee W, et al. Comparison of low and high volume irrigationaspiration systems for extracapsular cataract surgery. Am J Ophthalmol 1986;102:91-4.

16. Sugar J, Mitchelson J, Kraff M. The effect of phacoemulsification on corneal endothelial cell density. Arch Ophthalmol 1978:96:446-8.

17. Brasindice pharmaceutical guide. 2009. http://www.brasindice.com.br. Year 45

18. Behndig A, Karlsson K, Brannstrom T, et al. Corneal endothelial integrity in mice lacking extracellular superoxide dismutase. Invest Ophthalmol Vis Sci 2001:42:2784-8.

19. Ventura ACS, Walti R, Bohnke M. Corneal thickness and endothelial density before and after cataract surgery. Br J Ophthalmol 2001;85:18-20.

20. Kiss B, Findl O, Menapace R, et al. Corneal endothelial cell protection with a dispersive viscoelastic material and a irrigating solution during phacoemulsification. Low-cost versus expensive combination. J Cataract Refract Surg 2003;29:733-40.

21. Joussen AM, Barth $U$, Çubuk $H$, et al. Effect of irrigating solution and irrigation temperature on the cornea and pupil during phacoemulsification. $J$ Cataract Refract Surg 2000;26:392-7.

22. Vasavada V, Dixit NV, Raj SM, et al. Comparison between Ringer's lactate and balanced salt solution on postoperative outcomes after phacoemulsification: a randomized clinical trial. Indian J Ophthalmol 2009;57:191-5.

23. Yagoubi MI, Armitage WJ, Diamond J, et al. Effects of irrigation solutions on corneal endothelial function. Br J Ophthalmol 1994;78:302-6.

24. Edelhauser HF. The resiliency of the corneal endothelium to refractive and intraocular surgery. Cornea 2000;19:263-73.

25. McCarey BE, Polack FM, Marshall W. The phacoemulsification procedure. I. The effect of intraocular irrigating solutions on the corneal endothelium. Invest Ophthalmol 1976;15:449-57

26. McEnerney JK, Peyman GA. Simplification of glutathione-bicarbonate-Ringer solution: its effect on corneal thickness. Invest Ophthalmol Vis Sci 1977;16:657-60.

27. Nuyts RMMA, Edelhauser HF, Holley GP. Intraocular irrigating solutions: a comparison of Hartmann's lactated Ringer's solution, BSS and BSS Plus. Graefe's Arch Clin Exp Ophthalmol 1995;233:655-61.

28. Cheng H, Bates AK, Wood L, et al. Positive correlation of corneal thickness and endothelial cell loss. Serial measurements after cataract surgery. Arch Ophthalmol 1988;106:920-2 